Check for updates

Cite this: RSC Adv., 2017, 7, 30956

\title{
Synthesis of porous $\mathrm{ZnS}, \mathrm{ZnO}$ and $\mathrm{ZnS} / \mathrm{ZnO}$ nanosheets and their photocatalytic properties
}

\author{
Xiuyan Li, (DD *ab Xin Li, (D) a Bangyao Zhu, ${ }^{a}$ Jingshu Wang, ${ }^{a}$ Huixia Lan ${ }^{\mathrm{cd}}$ \\ and Xiaobo Chen ${ }^{\star b}$
}

Received 20th March 2017

Accepted 12th June 2017

DOI: $10.1039 / \mathrm{c} 7 \mathrm{ra03243a}$

rsc.li/rsc-advances

\begin{abstract}
Porous $\mathrm{ZnS}, \mathrm{ZnO}$ and $\mathrm{ZnS}-\mathrm{ZnO}$ nanosheets (NSs) are obtained by annealing ZnS(en) $)_{0.5}$ (en = ethylenediamine) NSs under suitable conditions in air. The annealing temperature plays an important role. Porous hexagonal wurtzite $\mathrm{ZnS}, \mathrm{ZnS}-\mathrm{ZnO}$ and $\mathrm{ZnO}$ NSs are obtained at 400, 500 and $600{ }^{\circ} \mathrm{C}$, respectively. ZnS-ZnO NSs exhibit the highest photocatalytic activity and good photocatalytic stability in the decomposition of organic dye molecule rhodamine $B(\mathrm{RhB})$ under ultraviolet (UV) light illumination.
\end{abstract}

\section{Introduction}

In recent years, many industries, such as textile and printing factories, have produced tremendous amounts of wastewater because of a heavy reliance on dyes and pigments. ${ }^{1,2}$ As is known, dye wastewater pollution can cause numerous serious problems in water environments, and also has a strong negative impact on human survival and development. Semiconductorbased photocatalysis can mineralize the various organic dyes in aqueous solution to $\mathrm{CO}_{2}, \mathrm{H}_{2} \mathrm{O}$ or other harmless products. ${ }^{3}$ Therefore, photocatalytic degradation of organic dyes has been regarded as a very efficient and inexpensive method of removing dye pollutants in wastewater. ${ }^{4}$

Recently, many semiconductor photocatalysts have been developed..$^{5-7}$ Among those photocatalysts, ZnO, with a wide band gap energy of $3.20 \mathrm{eV}$ and a large exciton binding energy (60 meV), has attracted much attention owing to its low toxicity, abundant morphologies, easy synthesis, and low cost. $^{.8-11}$ Similarly, ZnS, having a wide and direct band gap $\left(E_{g}=3.72 \mathrm{eV}\right.$ for hexagonal wurtzite phase and $E_{\mathrm{g}}=3.68 \mathrm{eV}$ for cubic zinc blende phase), is another promising photocatalyst because of its relatively high photocatalytic activity and natural abundance. ${ }^{12,13}$ Many $\mathrm{ZnO}$ or ZnS nanostructure have been synthesized through various methods. ${ }^{14-21}$ The properties and applications of nanomaterials are related to their morphologies and nanostructures, such as size, surface area and defect. 1-Dimensional (1D) $\mathrm{ZnO}$ (or $\mathrm{ZnS}$ ) nanomaterials, such as

${ }^{a}$ Key Laboratory of Functional Materials Physics and Chemistry of the Ministry of Education, Jilin Normal University, Siping 13600o, Jilin, China. E-mail: lixiuyan@ jlnu.edu.cn; Tel: +864343294566

${ }^{b}$ Department of Chemistry, University of Missouri-Kansas City, Kansas City, MO 64110, USA. E-mail: chenxiaobo@umkc.edu; Tel: +18162356420

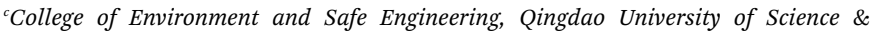
Technology, Qingdao, 266042, Shandong, China

${ }^{d}$ State Key Laboratory of Pulp and Paper Engineering, South China University of Technology, Guangzhou, 510640, Guangdong, China nanorods and nanowires, have been studied with a various techniques on their photocatalytic activities. ${ }^{22,23} 2$-Dimensional (2D) nanomaterials are attracting much attention recently due to their unique physical and chemical properties. ${ }^{24,25}$ Among 2D nanomaterials, porous nanomaterials are highly attractive to scientists for their high surface area and large pore volume towards enhanced photocatalytic activities in eliminating environmental hazards ${ }^{26,27}$ As most synthesis is complicated or costly, it is always highly attractive to synthesize porous $2 \mathrm{D}$ materials with a facile and low-cost route for photocatalytic applications.

In this study, porous $\mathrm{ZnS}, \mathrm{ZnO}$ and $\mathrm{ZnS}-\mathrm{ZnO}$ nanosheets (NSs) are fabricated by thermal treatment of ZnS(en $)_{0.5}$ NSs which are solvothermally synthesized using en as a single solvent. Their phase structures and morphologies are investigated with XRD, XPS, SEM, TEM and BET, and their photocatalytic properties are explored in detail.

\section{Experimental section}

\subsection{Preparation}

All reagents were analytical grade, purchased from Sinopharm Chemical Regent Co., Ltd, and used without further purification. The $\mathrm{ZnS}(\mathrm{en})_{0.5}$ precursor was prepared with a solvothermal method using ethylenediamine (en) as both a single solvent and a soft growth template. In a typical synthesis, $2 \mathrm{mmol}$ $\mathrm{Zn}\left(\mathrm{NO}_{3}\right)_{6} \cdot \mathrm{H}_{2} \mathrm{O}$ and $4 \mathrm{mmol} \mathrm{CS}\left(\mathrm{NH}_{2}\right)_{2}$ were dissolved in $60 \mathrm{~mL}$ en under stirring. After that, the solution was reacted in a $80 \mathrm{~mL}$ Teflon-lined stainless steel autoclave - at $180{ }^{\circ} \mathrm{C}$ for $12 \mathrm{~h}$. After cooled to room temperature, the precipitate was washed several times with distilled water and absolute ethanol alternately, and then dried in an oven at $60^{\circ} \mathrm{C}$ for $12 \mathrm{~h}$. The $\mathrm{ZnS}(\mathrm{en})_{0.5}$ NSs were obtained. The $\mathrm{ZnS}(\mathrm{en})_{0.5} \mathrm{NSs}$ was annealed at $400^{\circ} \mathrm{C}, 500^{\circ} \mathrm{C}$ and $600{ }^{\circ} \mathrm{C}$ for $2 \mathrm{~h}$ in an electrical furnace in air to obtain $\mathrm{ZnS}$, ZnS$\mathrm{ZnO}$, and ZnO NSs, respectively. 


\subsection{Characterization}

The morphologies and crystalline nature were characterized by field emission scanning electron microscopy (FESEM, JEOL JSM-7800F) and transmission electron microscopy (TEM, FEI Tenai $\mathrm{G}^{2}$ F20 microscope). The phase constituents were determined using X-ray diffraction (XRD, Rigaku-D/max-2500 diffractometer). The elemental compositions were measured by X-ray photoelectron spectroscopy (XPS, Thermo Scientific ESCALAB 250Xi A1440 system). The Brunauer-Emmett-Teller (BET) special surface areas were measured on a nitrogen adsorption apparatus (AUTOSORB-IQ, Quantachrome Instruments, USA) using $\mathrm{N}_{2}$ as the adsorbate. The pore size distributions were calculated by the Barrett-Joyner-Halenda (BJH) method. UV-vis diffuse reflectance spectra (DRS) were carried out on a SHIMADZU-UV-3600 spectrophotometer at room temperature. The room temperature photoluminescence (PL) spectra were preformed on a Renishaw inVia micro-PL spectrometer with a $325 \mathrm{~nm} \mathrm{He-Cd}$ laser as the excitation source.

\subsection{Photocatalysis}

The photodecomposition of RhB was used to study the photocatalytic properties of the as-synthesized samples. A $250 \mathrm{~W}$ high-pressure mercury lamp (main emission wavelength $\lambda=365$ $\mathrm{nm}$ ) was used as UV light source. All photocatalytic reactions were carried out at room temperature. Prior to UV light exposure, the suspension was stirred in the dark for $30 \mathrm{~min}$ to equilibrate the adsorption and desorption of RhB molecules. For comparison, blank photodegradation experiment was performed without adding photocatalyst. After certain irradiation intervals, the solution of RhB was analyzed by a UV-vis spectrophotometer (UV-5800PC, Shanghai Metash Instruments Co., Ltd).

\section{Results and discussion}

Fig. 1 shows the SEM images of the as-prepared $\mathrm{ZnS}(\mathrm{en})_{0.5}, \mathrm{ZnS}$, $\mathrm{ZnS}-\mathrm{ZnO}$ and $\mathrm{ZnO}$. $\mathrm{ZnS}(\mathrm{en})_{0.5}$ has a sheet-like morphology with regular rectangles, and lateral dimensions are in the range of $0.2-2 \mu \mathrm{m}$. In addition, the surfaces of $\mathrm{ZnS}(\mathrm{en})_{0.5}$ are quite smooth. The high-magnification SEM image in Fig. 1(a2) shows that the thickness of $\mathrm{ZnS}(\mathrm{en})_{0.5}$ is approximately $60 \mathrm{~nm}$. Fig. 3(b-d) show the samples obtained by annealing the ZnS(en) $)_{0.5}$ NSs at various temperatures in air. These images present that the sizes (dimension and thickness) and shape of $\mathrm{ZnS}$, ZnS-ZnO and ZnO NSs are similar to that of ZnS(en $)_{0.5}$ NSs. However, the surfaces of $\mathrm{ZnS}, \mathrm{ZnS}-\mathrm{ZnO}$ and $\mathrm{ZnO}$ have changed. Fig. 1(b1) shows the surface of ZnS NSs becomes a little rough, due to the pores formed by the removal of en. ${ }^{14}$ Compared with that of $\mathrm{ZnS} \mathrm{NSs}$, the surface of $\mathrm{ZnS}-\mathrm{ZnO} \mathrm{NSs}$ is relatively rougher. There are numerous small pores on the surface of ZnSZnO NSs. As shown in Fig. 1(d), ZnO NSs are composed of nanoparticles with $\sim 60 \mathrm{~nm}$ in size, and the thickness of $\mathrm{ZnO}$ NSs is about the size of one nanoparticle. Meanwhile, there are numerous pores with a size distribution from 20 to $50 \mathrm{~nm}$ on the surface of ZnO NSs. It is proposed that the formation of
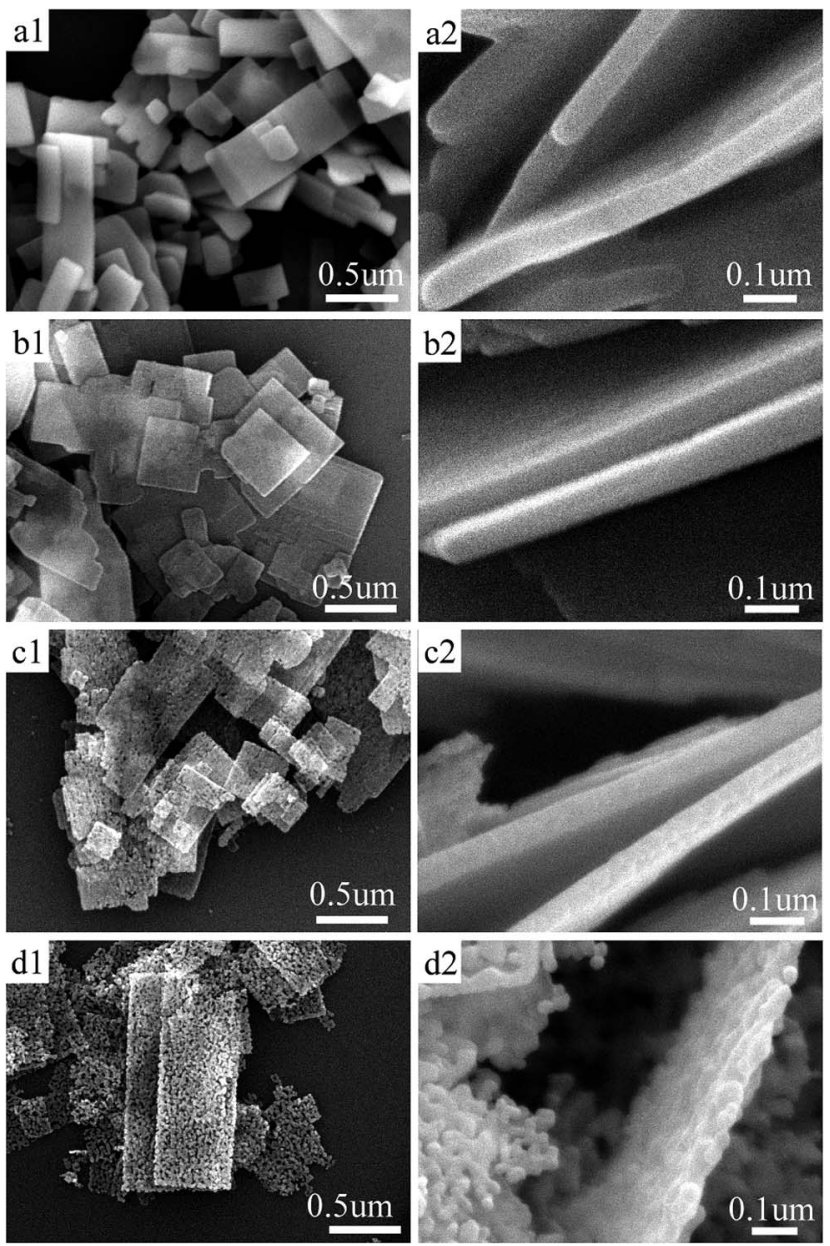

Fig. 1 Low and high-magnification SEM images of (a) ZnS(en) 0.5 , (b) $\mathrm{ZnS}$, (c) $\mathrm{ZnS}-\mathrm{ZnO}$ and (d) $\mathrm{ZnO}$.

porous structure of $\mathrm{ZnO}$ NSs is from the atomic substitution of sulfur by oxygen. ${ }^{28}$

The microstructures of $\mathrm{ZnS}, \mathrm{ZnS}-\mathrm{ZnO}$ and $\mathrm{ZnO}$ NSs are further characterized with TEM and the corresponding results are shown in Fig. 2. Fig. 2(a1, b1 and c1) show the TEM images of $\mathrm{ZnS}, \mathrm{ZnS}-\mathrm{ZnO}$ and $\mathrm{ZnO}$ NSs, respectively. It is obviously seen that all samples exhibit the profile of planar sheets with widths of $0.2-1 \mu \mathrm{m}$ and lengths of $0.5-2 \mu \mathrm{m}$, which agree well with the observation of SEM images (Fig. 1(b-d)). The HRTEM image in Fig. 2(a2) clearly shows that the planar spacing of about $0.31 \mathrm{~nm}$ corresponds well to the (002) plane of hexagonal wurtzite-type $\mathrm{ZnS}$, meaning that ZnS NSs grow along the $\langle 001\rangle$ direction $(c$ axis). The corresponding SAED pattern in Fig. 2(a3) reveals that ZnS NSs is single crystalline. Fig. 2(b1) shows the TEM image of $\mathrm{ZnS}-\mathrm{ZnO}$ NSs, and the surface of ZnS-ZnO NSs is rougher than that of ZnS NSs. The HRTEM image of ZnS-ZnO NSs in Fig. 2(b2) clearly shows three different crystal parts. One set (in A area) of the planar spacing of about $0.26 \mathrm{~nm}$ corresponds to the (002) plane of hexagonal wurtzite-type $\mathrm{ZnO}$, and other set (in $B$ area) of the lattice fringe of approximate $0.31 \mathrm{~nm}$ matches well with the lattice spacing of the (002) plane of hexagonal wurtzitetype ZnS. The corresponding FFT patterns of these two set HRTEM images are shown in Fig. 2(b3 and b5), respectively. 

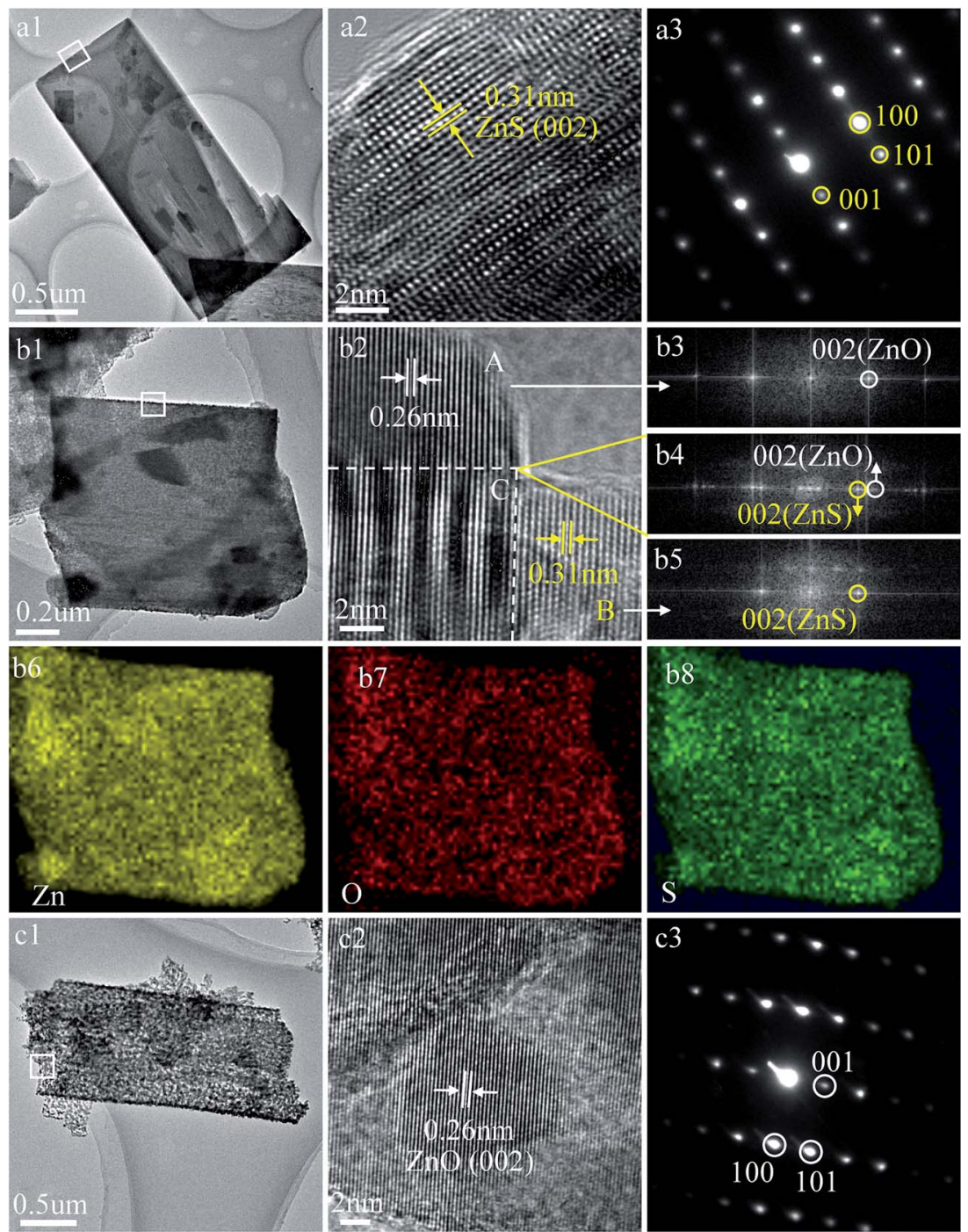

Fig. 2 TEM images, HRTEM images and corresponding SAED (or FFT) patterns of (a1-a3) ZnS, (b1-b5) ZnS-ZnO and (c1-c3) ZnO (b6-b8) are EELS elemental mapping images of $\mathrm{Zn}, \mathrm{O}$, and $\mathrm{S}$ of $\mathrm{ZnS}-\mathrm{ZnO}$ NSs, respectively.

Another FFT pattern in Fig. 2(b4) belonging to $\mathrm{C}$ area (in Fig. 2(b2)) implies the coexistence of $\mathrm{ZnS}$ and $\mathrm{ZnO}$ phases in this area. Fig. 2(b6-b8) display EELS elemental mapping images of $\mathrm{Zn}, \mathrm{O}$, and S, respectively, indicating that $\mathrm{Zn}, \mathrm{O}$, and $\mathrm{S}$ atoms are uniformly distributed in ZnS-ZnO NSs. As shown in Fig. 2(c1), the as-prepared ZnO possesses a sheet morphology composed of nanoparticles and non-uniform pores, consistent with the observation of SEM image (Fig. 1(d)). The HRTEM image in Fig. 2(c2) shows that the lattice spacing is $0.26 \mathrm{~nm}$, which corresponds well to the $d$-values of hexagonal $\mathrm{ZnO}(002)$. The discrete spots in the SAED pattern in Fig. 2(c3) indicate that the as-prepared porous ZnO NSs have a single crystalline nature. Namely, the nanoparticles have the same orientation, consistent with those reported in the ref. 29.

To further investigate the compositions and purity of ZnS and ZnO NSs, XPS are carried out and the results of binding energy spectra are shown in Fig. 3. The survey spectrum in Fig. 3(a) shows the presence of the $\mathrm{Zn}, \mathrm{S}, \mathrm{O}$ and $\mathrm{C}$ peaks in $\mathrm{ZnS}$
NSs, and the peaks of Zn, O and $\mathrm{C}$ in the ZnO NSs. The carbon peak in both ZnS and ZnO NSs mainly originates from the adventitious hydrocarbon from the XPS instrument itself. ${ }^{30,31}$ The weak peak of $\mathrm{O}$ in ZnS NSs is mainly attributed to $\mathrm{H}_{2} \mathrm{O}$, or $\mathrm{OH}^{-}$adsorbed on the surfaces of ZnS NSs. ${ }^{32}$ Fig. 3(b-d) show the core-level XPS spectra of Zn 2p, S 2p, and O 1s, respectively. Fig. 3(b) exhibits the $\mathrm{Zn}^{2+} 2 \mathrm{p}_{3 / 2}$ and $\mathrm{Zn}^{2+} 2 \mathrm{p}_{1 / 2}$ peaks are assigned to $\mathrm{Zn}^{2+} \cdot{ }^{33,34}$ However, the peak location of $\mathrm{Zn}$ is different between ZnS and ZnO NSs. For the Zn 2p spectra, the ZnO NSs shows peak-shifting towards higher binding energy in comparison with ZnS NSs, consistent with the values reported in literature. ${ }^{35}$ As shown in Fig. 3(c), the peaks at 162.0 and $163.2 \mathrm{eV}$ are attributed to $\mathrm{S} 2 \mathrm{p}_{3 / 2}$ and $\mathrm{S} 2 \mathrm{p}_{1 / 2}$ of $\mathrm{S}^{2-}$, respectively. ${ }^{36,37}$ The peak at $532.4 \mathrm{eV}$ in Fig. $3(\mathrm{~d})$ is assigned to $\mathrm{O}^{2-}$ 1s in ZnO. Consequently, these results indicate that ZnS(en $)_{0.5}$ NSs completely convert into ZnS NSs when the annealing temperature is $400{ }^{\circ} \mathrm{C}$, and pure ZnO NSs are obtained when the annealing temperature increases to $600{ }^{\circ} \mathrm{C}$. 

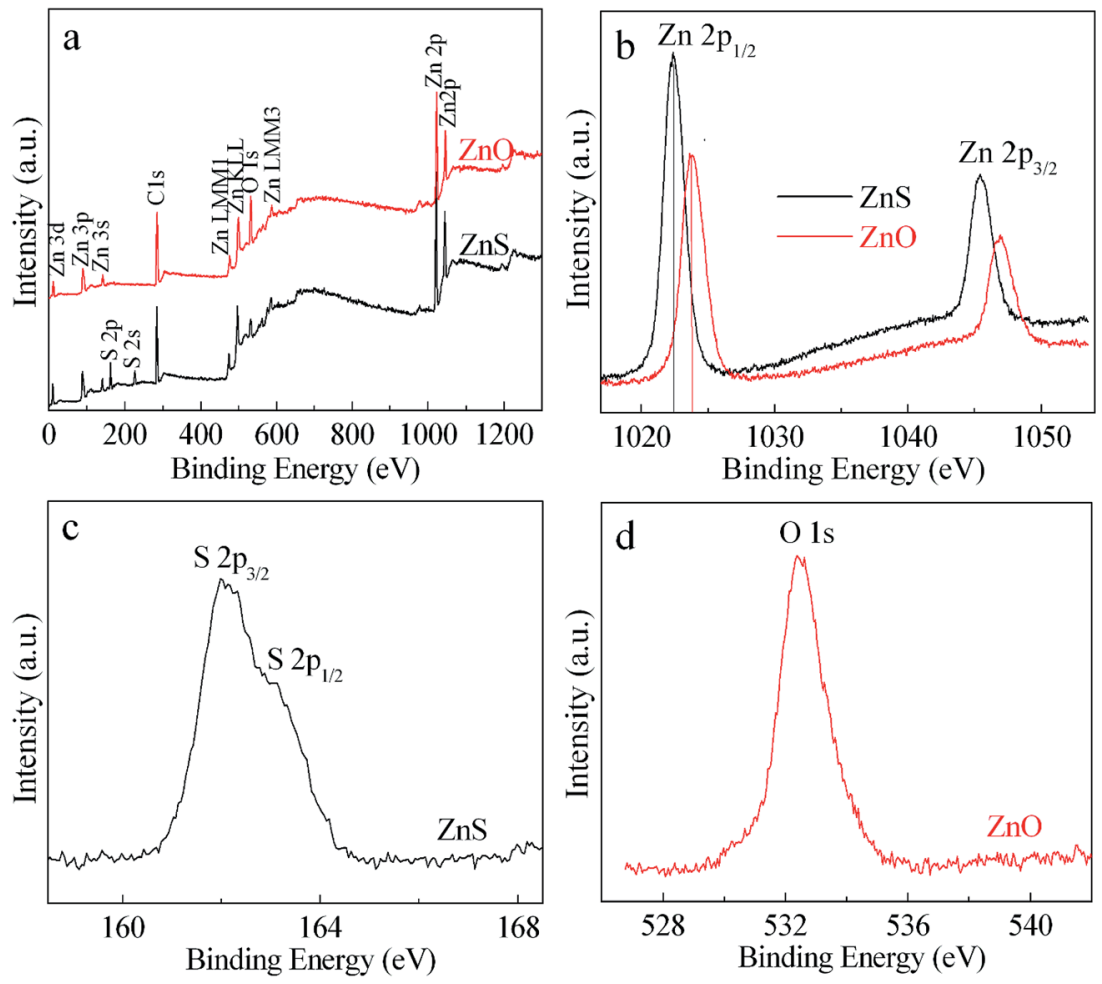

Fig. 3 Typical XPS analysis of ZnS-ZnO NSs, (a) survey spectrum, (b) Zn 2p, (c) S 2p, and (d) O 1s.

Fig. 4 shows the XRD patterns of the as-prepared samples. All the diffraction peaks of Fig. 4(a) can be well indexed to orthorhombic structure $\mathrm{ZnS}(\mathrm{en})_{0.5}$, which is in good agreement with those reported in the literatures. ${ }^{\mathbf{1 4 , 3 8 - 4 0}}$ And the strong and sharp diffraction peaks in the XRD pattern imply good crystallinity of $\mathrm{ZnS}(\mathrm{en})_{0.5}$. When the $\mathrm{ZnS}(\mathrm{en})_{0.5}$ complex is annealed at different temperature under air atmosphere, its structure changes completely. All the diffraction peaks of Fig. 4(b) fit quite well the standard hexagonal wurtzite structure ZnS (JCPDS no. 36-1450), implying that the precursor completely converts into $\mathrm{ZnS}$ after $2 \mathrm{~h}$ of thermal annealing at $400{ }^{\circ} \mathrm{C}$. By increasing the annealing temperature to $500{ }^{\circ} \mathrm{C}$, the XRD pattern (Fig. 4(c)) consists of two sets of diffraction peaks of ZnS and ZnO (JCPDS no. 361451), demonstrating that $\mathrm{ZnS}$ phase progressively transforms

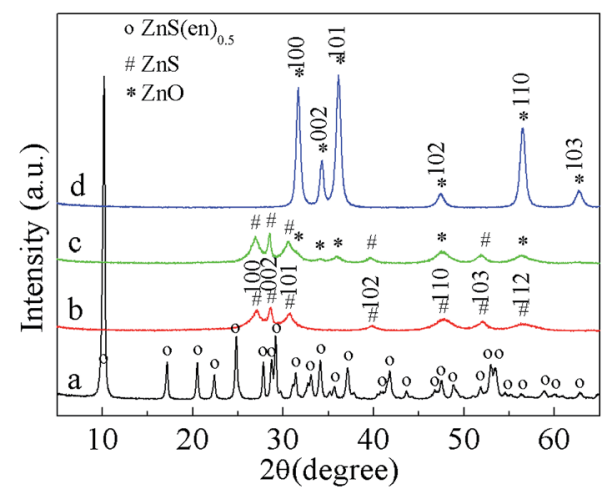

Fig. 4 XRD patterns of (a) ZnS(en) ${ }_{0.5}$, (b) ZnS, (c) ZnS-ZnO and (d) $\mathrm{ZnO}$. into wurtzite ZnO. When the annealing temperature further increases to $600{ }^{\circ} \mathrm{C}$, only peaks of $\mathrm{ZnO}$ are detected (Fig. 4(d)), indicating that $\mathrm{ZnS}$ is completely oxidized into $\mathrm{ZnO}$. This result indicates that the annealing temperature is the main factor to affect the conversion from $\mathrm{ZnS}$ to $\mathrm{ZnO}$.

Fig. 5(a) shows the $\mathrm{N}_{2}$ adsorption-desorption isotherms of $\mathrm{ZnS}(\mathrm{en})_{0.5}$, ZnS, ZnS-ZnO and ZnO NSs. According to Fig. 5(a), no obvious hysteresis loop in $\mathrm{ZnS}(\mathrm{en})_{0.5}$ NSs is detected. However, other samples exhibit typical adsorption-desorption isotherms characteristic of mesoporous materials. The special surface areas of the as-prepared samples are calculated according to the BET (Brunauer-Emmett-Teller) equation, and the corresponding results are summarized in Table 1. $\mathrm{ZnS}-\mathrm{ZnO}$ NSs show the biggest BET-specific surface area $\left(S_{\mathrm{BET}}\right)$ among all samples.

The pore size distributions of the as-prepared samples are calculated by the Barrett-Joyner-Halenda (BJH) method from the desorption branch of the isotherm curve, and the corresponding results are shown in Fig. 5(b). Obviously, ZnS(en) $)_{0.5}$ NSs have virtually no pore in the measurement range, which is in good agreement with the reported results. ${ }^{14,41}$ Generally, the sizes of pores increase with the increasing of annealing temperature. Moreover, the pore size distribution becomes broader with the increase of annealing temperature. ZnS NSs and ZnS-ZnO NSs have relative narrow distributions and the average pore size distribution is around 4 and $6 \mathrm{~nm}$, respectively. ZnO NSs have a broad pore size distribution from 20 to $50 \mathrm{~nm}$. The total pore volumes of all samples are listed in Table 1. 

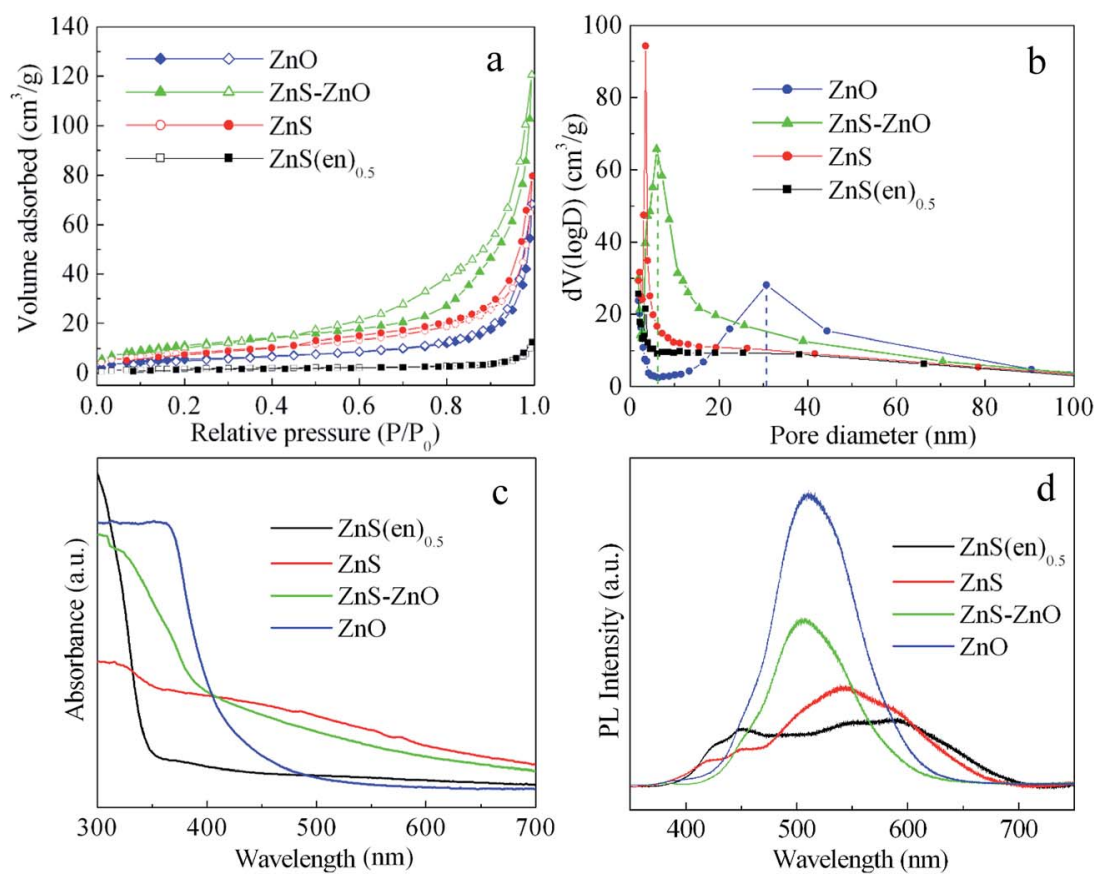

Fig. 5 (a) $\mathrm{N}_{2}$ adsorption-desorption isotherms, (b) pore size distribution curves, (c) UV-vis DRS and (d) room-temperature PL spectra of $\mathrm{ZnS}(\mathrm{en})_{0.5}, \mathrm{ZnS}, \mathrm{ZnS}-\mathrm{ZnO}$ and $\mathrm{ZnO} \mathrm{NSs}$.

Table $1 S_{\mathrm{BET}}$ and pore volume $\left(V_{\mathrm{p}}\right)$ of samples

\begin{tabular}{llll}
\hline Sample & Annealing $T\left({ }^{\circ} \mathrm{C}\right)$ & $S_{\text {BET }}\left(\mathrm{m}^{2} \mathrm{~g}^{-1}\right)$ & $V_{\mathrm{p}}\left(\mathrm{cm}^{3} \mathrm{~g}^{-1}\right)$ \\
\hline ZnS(en $)_{0.5}$ & - & 10.90 & 0.084 \\
ZnS & 400 & 29.39 & 0.121 \\
ZnS-ZnO & 500 & 40.83 & 0.184 \\
ZnO & 600 & 19.71 & 0.141
\end{tabular}

The optical properties of the as-prepared samples are characterized by UV-vis DRS and PL spectra analyses. Fig. 5(c) presents the UV-vis DRS of ZnS(en $)_{0.5}, \mathrm{ZnS}, \mathrm{ZnS}-\mathrm{ZnO}$ and $\mathrm{ZnO}$

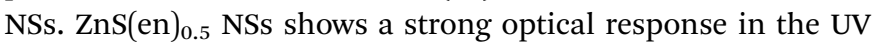
region. ZnS NSs clearly displays a strong absorption both in the UV region from bandgap transition and in the visible region from defects. The absorption of $\mathrm{ZnS}-\mathrm{ZnO}$ NSs shows a large UV absorption and a small absorption in the visible range. The spectrum of ZnO NSs shows a sharp edge at about $380 \mathrm{~nm}$, which is related to its band-edge absorption of $\mathrm{ZnO}$ semiconductor material. ${ }^{42}$

Fig. 5(d) shows the room-temperature PL spectra of the asprepared samples. According to Fig. 5(d), two major emissions centered at about 450 and $600 \mathrm{~nm}$ are detected in $\mathrm{ZnS}(\mathrm{en})_{0.5}$ NSs. ZnS NSs shows an obviously strong green emission band centered at approximately $540 \mathrm{~nm}$, which originates from some structural defects such as point defects or oxygen defects. ${ }^{\mathbf{4 1 , 4 4}}$ ZnS-ZnO and ZnO NSs display an obviously strong green emission band centered at around $510 \mathrm{~nm}$, which can be attributed to surface defects coming from $\mathrm{ZnS}$ or $\mathrm{ZnO}$ crystal. ${ }^{\mathbf{4 5 , 4 6}}$ It is worth to note that visible light emission peaks increase with the increasing of $\mathrm{ZnS}(\mathrm{en})_{0.5}$ NSs annealing temperature.
The photocatalytic activities of the as-prepared samples are evaluated and compared by measuring the decomposition of RhB aqueous solution under UV light illumination. Fig. 6(a) presents the degradation efficiency versus irradiation time for the different photocatalysts. For comparison, blank experiment in the absence of photocatalyst is preformed, and no appreciable degradation of $\mathrm{RhB}$ is detected after $90 \mathrm{~min}$. In contrast, the RhB dramatic degrades when the as-prepared samples are employed as photocatalysts. According to Fig. 6(a), the photocatalytic activities decrease in the order of $\mathrm{ZnS}-\mathrm{ZnO}>\mathrm{ZnS}>\mathrm{ZnO}$

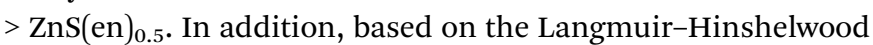
model, the degradation of dyes can be described by an apparent first-order equation, $\ln \left(C_{0} / C_{t}\right)=k t$, where $C_{0}$ is the dye initial concentration, $C_{t}$ is the remaining concentration, $t$ is illumination time and $k$ is the apparent first-order rate constant. ${ }^{\mathbf{4 1 , 4 3}}$ Fig. 6(b) shows the $\ln \left(C_{0} / C\right)$ versus irradiation time for the different photocatalysts and corresponding rate constant. Clearly, ZnS-ZnO NSs shows the highest rate constant, whereas $\mathrm{ZnS}(\mathrm{en})_{0.5}$ NSs has the lowest.

In order to examine the stability of the catalyst, cycling experiments of degradation $\mathrm{RhB}$ aqueous solution over $\mathrm{ZnS}-$ ZnO NSs are carried out under identical reaction condition. As shown in Fig. 6(c), the photocatalytic activity of ZnS-ZnO NSs has no obviously drop after five cycles of experimental tests. This demonstrates the good photocatalytic stability of $\mathrm{ZnS}-\mathrm{ZnO}$ NSs.

Fig. 6(d) displays the relationship between the photocatalytic activity and $S_{\mathrm{BET}}$ of samples. It is interesting to notice that two curves have the similar order. This illustrates that there is a potential correlation between $S_{\text {BET }}$ and photocatalytic activity of those photocatalysts. The adsorption capacities of all as- 

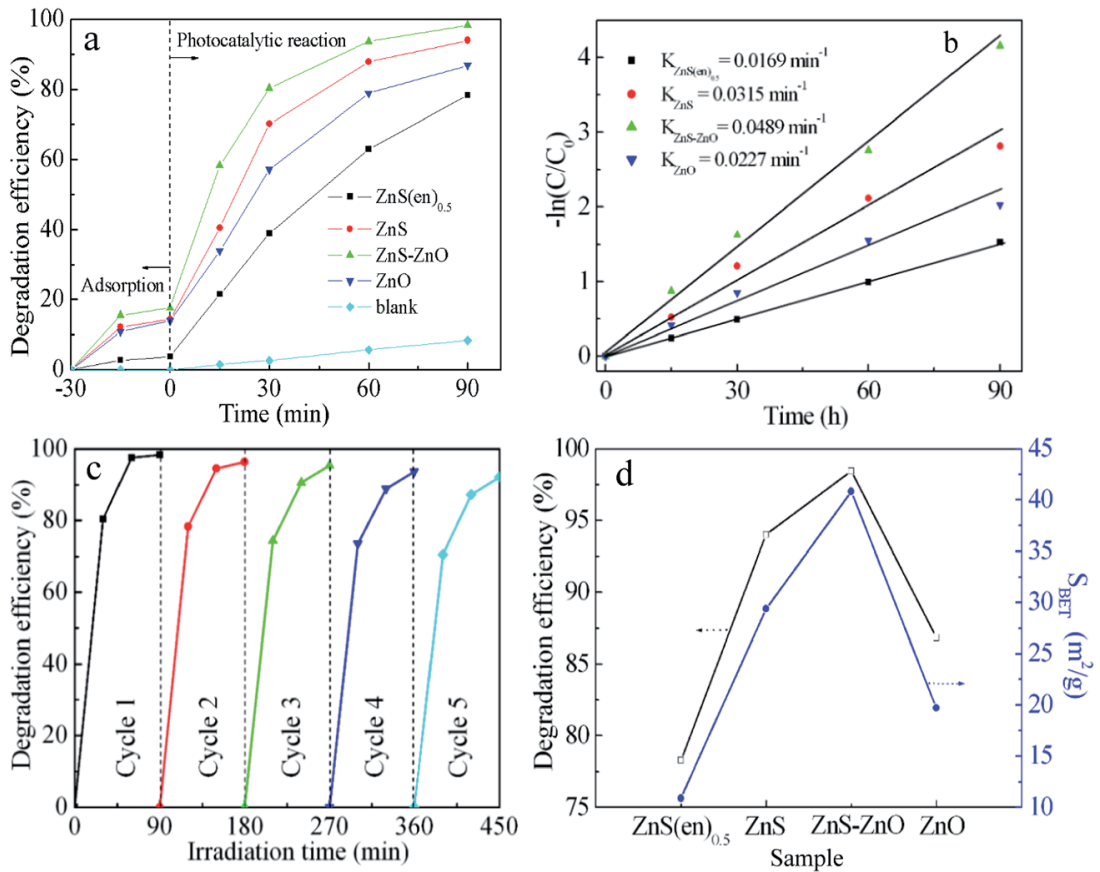

Fig. 6 (a) Degradation efficiency of RhB, and (b) $\ln \left(C_{0} / C\right)$ versus irradiation time for different photocatalysts. (c) Recycling experiments for the degradation of RhB using ZnS-ZnO NSs as photocatalyst. (d) Photocatalytic activities versus $S_{\mathrm{BET}}$ for the different photocatalysts.

prepared samples are investigated before the photocatalytic experiments. According to Fig. 6(a), the adsorption capacity of sample is proportional to its surface area. As we know, organic dye molecules can be degraded only when they are adsorbed by the catalyst surface. ${ }^{47,48}$ Photocatalyst with big surface area will adsorb more organic dye molecules. Accordingly, ZnS-ZnO NSs with the biggest $S_{\mathrm{BET}}$ exhibits the highest photocatalytic activity among all as-prepared samples. Furthermore, the outstanding photocatalytic activity of ZnS-ZnO NSs can be attributed to synergistic effect between $\mathrm{ZnS}$ and $\mathrm{ZnO}$, in that the photoexcited electrons and holes can be effectively separated into the $\mathrm{ZnS}$ and ZnO parts, respectively, due to the mismatch of the electronic structures of the ZnS and ZnO. Therefore, ZnS-ZnO NSs show remarkable photocatalytic activity over pure ZnS or ZnO NSs.

\section{Conclusions}

In summary, porous $\mathrm{ZnS}$, ZnO and ZnS-ZnO NSs are successfully synthesized via simple thermal annealing of $\mathrm{ZnS}(\mathrm{en})_{0.5}$ complex precursor in air atmosphere. The morphology of $\mathrm{ZnS}(\mathrm{en})_{0.5}$ NSs is preserved throughout the conversion process, and $\mathrm{ZnS}$ and $\mathrm{ZnO}$ NSs have the same hexagonal structure. ZnSZnO NSs show the highest photocatalytic activity due to theirs the biggest specific surface area and special heterostructure. In addition, ZnS-ZnO NSs exhibit a good stability. Therefore, ZnSZnO NSs would be a good photocatalyst with a extensive potential use for sewage water treatment.

\section{Acknowledgements}

This work is supported by the National Natural Science Foundation of China (Grant No. 61378085, 61308095, 11404137 and
51608226) and State Key Laboratory of Pulp and Paper Engineering (201522). X. C. acknowledges the support from the College of Arts and Sciences, University of Missouri - Kansas City, and University of Missouri Research Board.

\section{References}

1 O. Ozdemir, B. Armagan, M. Turan and M. S. Celik, Dyes Pigm., 2004, 62, 49-60.

2 S. B. Wang, H. T. Li, S. J. Xie, S. L. Liu and L. Y. Xu, Chemosphere, 2006, 65, 82-87.

3 R. Andreozzi, V. Caprio, A. Insola and R. Marotta, Catal. Today, 1999, 53, 51-59.

4 O. Legrini, E. Oliveros and A. M. Braun, Chem. Rev., 1993, 93, 671-698.

5 M. N. Chong, B. Jin, C. W. K. Chow and C. Saint, Water Res., 2010, 44, 2997-3027.

6 S. G. Kumar and K. S. R. K. Rao, Appl. Surf. Sci., 2017, 391, 124-148.

7 X. Y. Li, X. Li, J. Wang, H. J. Zhai and X. B. Chen, J. Mater. Sci., 2017, 52, 3821-3830.

8 S. G. Kumar and K. S. R. K. Rao, RSC Adv., 2015, 5, 3306-3351. 9 J. Gupta, J. Mohapatra and D. Bahadur, Dalton Trans., 2017, 46, 685-696.

10 X. Q. Gu, C. Y. Li, S. Yuan, M. G. Ma, Y. H. Qiang and J. F. Zhu, Nanotechnology, 2016, 27, 402001.

11 X. Y. Li, J. Wang, J. H. Yang, J. H. Lang, X. W. Meng, X. F. Li and Y. R. Sui, J. Mol. Catal. A: Chem., 2013, 378, 1-6.

12 X. Fang, T. Zhai, U. K. Gautam, L. Li, L. Wu, Y. Bando and D. Golberg, Prog. Mater. Sci., 2011, 56, 175-287.

13 L. X. Hu, F. Y. Chen, P. F. Hu, L. P. Zou and X. Hu, J. Mol. Catal. A: Chem., 2016, 411, 203-213. 
14 J. S. Jang, C. J. Yu, S. H. Choi, S. M. Ji, E. S. Kim and J. S. Lee, J. Catal., 2008, 254, 144-155.

15 C. C. Lu, X. Y. Hu, K. B. Shi, Q. Hu, R. Zhu, H. Yang and Q. H. Gong, Light: Sci. Appl., 2015, 4, 302.

16 X. Y. Li, F. H. Zhao, J. X. Fu, X. F. Yang, J. Wang, C. L. Liang and M. M. Wu, Cryst. Growth Des., 2009, 9, 409-413.

17 Y. I. Choia, S. Lee, S. K. Kim, Y. Kim, D. W. Cho, M. M. Khan and Y. K. Sohn, J. Alloys Compd., 2016, 675, 46-56.

18 P. K. Shrestha, Y. T. Chun and D. Chu, Light: Sci. Appl., 2015, 4, 259.

19 Q. Ma, Y. Q. Wang, J. H. Kong and H. X. Jia, Ceram. Int., 2016, 42, 2854-2860.

20 S. K. Li, Z. G. Wu, W. H. Li, Y. Liu, R. F. Zhuo, D. Yan, W. Jun and P. X. Yan, CrystEngComm, 2013, 15, 1571-1577.

21 Y. Y. Lai, Y. P. Lan and T. C. Lu, Light: Sci. Appl., 2013, 2, 76. 22 B. Pal and B. Pal, Chem. Eng. J., 2015, 263, 200-208.

23 X. Y. Li, J. Wang, J. H. Yang, S. Q. Lü, X. W. Meng, J. H. Lang, X. F. Li and Y. R. Sui, J. Alloys Compd., 2013, 580, 205-210.

$24 \mathrm{J.} \mathrm{Li}$, H. Q. Fan and X. H. Jia, J. Phys. Chem. C, 2010, 114, 14684-14691.

25 M. Chen, Z. H. Wang, D. M. Han, F. B. Gu and G. S. Guo, J. Phys. Chem. C, 2011, 115, 12763-12773.

26 L. L. Xu, Z. M. Li, Q. H. Cai, H. X. Wang, H. Gao, W. Lv and J. Liu, CrystEngComm, 2010, 12, 2166-2172.

27 Y. Hong, C. G. Tian, B. J. Jiang, A. P. Wu, Q. Zhang, G. H. Tian and H. G. Fu, J. Mater. Chem. A, 2013, 1, 5700-5708.

28 J. Y. Liu, Z. Guo, F. L. Meng, T. Luo, M. Q. Li and J. H. Liu, Nanotechnology, 2009, 20, 125501.

29 L. Nasi, D. Calestani, F. Fabbri, P. Ferro, T. Besagni, P. Fedeli, F. Licci and R. Mosca, Nanoscale, 2013, 5, 10601066.

30 Y. Chi, Q. Yuan, Y. J. Li, L. Zhao, N. Li, X. T. Li and W. F. Yan, J. Hazard. Mater., 2013, 262, 404-411.

31 F. Xu, Y. F. Yuan, H. J. Han, D. P. Wu, Z. Y. Gao and K. Jiang, CrystEngComm, 2012, 14, 3615-3622.
32 J. G. Yu, J. Zhang and S. W. Liu, J. Phys. Chem. C, 2010, 114, 13642-13649.

33 X. Yang, H. T. Xue, J. Xu, X. Huang, J. Zhuang, Y. B. Tang, T. W. Ng, H. L. Kwong, X. M. Meng and C. S. Lee, ACS Appl. Mater. Interfaces, 2014, 6, 9078-9084.

34 W. D. Shi, J. Q. Shi, S. Yu and P. Liu, Appl. Catal., B, 2013, 138-139, 184-190.

35 L. H. Yu, W. Chen, D. Z. Li, J. B. Wang, Y. Shao, M. He, P. Wang and X. Z. Zheng, Appl. Catal., B, 2015, 164, 453-461.

36 S. Liu, X. T. Wang, W. X. Zhao, K. Wang, H. X. Sang and Z. He, J. Alloys Compd., 2013, 568, 84-91.

37 D. A. Reddy, R. Ma, M. Y. Choi and T. K. Kim, Appl. Surf. Sci., 2015, 324, 725-735.

38 L. Nasi, D. Calestani, T. Besagni, P. Ferro, F. Fabbri, F. Licci and R. Mosca, J. Phys. Chem. C, 2012, 116, 6960-6965.

39 X. Wu, K. W. Li and H. Wang, J. Hazard. Mater., 2010, 174, 573-580.

40 Z. X. Deng, C. Wang, X. M. Sun and Y. D. Li, Inorg. Chem., 2002, 41, 869-873.

41 J. G. Zhao, J. Z. Yin and M. Yang, J. Alloys Compd., 2013, 579, 45-49.

42 H. H. Yin, K. Yu, C. Q. Song, R. Huang and Z. Q. Zhu, ACS Appl. Mater. Interfaces, 2014, 6, 4851-14860.

43 X. Li, T. Xia, C. H. Xu, J. Murowchick and X. B. Chen, Catal. Today, 2014, 225, 64-73.

44 L. Nasi, D. Calestani, F. Fabbri, P. Ferro, T. Besagni, P. Fedeli, F. Licci and R. Mosca, Nanoscale, 2013, 5, 10601066.

45 V. Ischenko, S. Polarz, D. Grote, V. Stavarache, K. Fink and M. Driess, Adv. Funct. Mater., 2015, 15, 1945-1954.

46 J. M. Xu, H. X. Sang, X. T. Wang and K. Wang, Dalton Trans., 2015, 44, 9528-9537.

47 X. Y. Li, J. Wang, J. H. Yang, J. H. Lang, X. W. Meng, X. F. Li and Y. R. Sui, J. Mol. Catal. A: Chem., 2013, 378, 1-6.

48 M. R. Hoffmann, S. T. Martin, D. W. Choi and D. W. Bahnemann, Chem. Rev., 1995, 95, 69-96. 